\title{
TUTORIA PEDAGÓGICA EM TEMPOS DE CULTURA DIGITAL: HAVERÁ ESPAÇO PARA A AFETIVIDADE?
}

\author{
PEDAGOGICAL TUTORSHIP IN TIMES OF DIGITAL CULTURE: WILL THERE BE ROOM FOR \\ AFFECTIVITY? \\ TUTORÍA PEDAGÓGICA EN TIEMPOS DE CULTURA DIGITAL: ¿HAY UN ESPACIO PARA LA \\ AFECTIVIDAD?
}

\author{
Cristiano da Cruz Fraga \\ Mestrando em Educação em Ciências - Universidade Federal do Rio Grande do Sul- UFRGS. \\ Email: dacruzfraga@yahoo.com.br. \\ Orcid: https://orcid.org/0000-0001-8657-9831
}

\author{
Cecilia Decarli \\ Doutoranda em Educação em Ciências -Universidade Federal do Rio Grande do Sul- UFRGS. E-mail: \\ cecilia_decarli@hotmail.com. \\ Orcid: https://orcid.org/0000-0003-4941-8419
}

\section{Cíntia Inês Boll}

Doutora em Educação -Universidade Federal do Rio Grande do Sul-UFRGS. E-mail: cintiaboll@gmail.com.

Orcid: https://orcid.org/0000-0003-1089-3271

\begin{abstract}
RESUMO
O artigo tem por objetivo apresentar ponderações relacionadas à atuação do tutor na Educação a Distância - EaD, em meio às possibilidades apresentadas no ensino perante o contexto da Cultura Digital e das necessidades emergentes do uso da afetividade nas relações pessoais e digitais aos estudantes que se enquadram nessa modalidade de ensino. $O$ delineamento desta obra baseia-se na potencialização da EaD através do trabalho afetivo do tutor que, por meio dos atributos técnicos e inteligível ao sensível, pode contribuir para a permanência do estudante e, ainda, para a credibilidade e respeito da sociedade perante a EaD. O presente estudo baseia-se em autores renomados no âmbito da EaD, da afetividade e da Cultura Digital no ensino, tais como Freire, Piaget, Wallon, Alves, Kensky, Fraga, entre outros estudiosos e as atuais legislações vinculadas a discussão. O trabalho verificou que a atuação do tutor na EaD no contexto de Cultura Digital está intrinsecamente relacionado a processos pedagógicos que visam o vínculo humanístico com os estudantes, conectando sentimentos e interação virtual simultaneamente sob diferentes olhares ao processo de ensino-aprendizagem, desencadeando a autonomia, o desejo e a motivação para permanência do estudante. Este estudo torna-se um instrumento de consulta de informações para a construção de ementas curriculares que desencadeiam habilidades relacionadas a afetividade no ensino superior a distância e estejam em consonância ao que propõe a Base Nacional Comum Curricular- BNCC para a formação de professores.
\end{abstract}

Palavras-chave: Tutor. BNCC. Afetividade.

\section{ABSTRACT}

This article aims to present weightings related to the tutor's performance in Distance Learning, amid the possibilities presented in teaching in the context of Digital Culture and the emerging needs of the use of 
affectivity in personal and digital relationships to students who fit this teaching modality. The design of this work is based on the maximization of Distance Education, through the affective work of the tutor who, through the technical attributes and intelligible to the sensitive, can contribute to the continuity of the student and, too, to the credibility and respect of society regarding Distance Education. This study is based on renowned authors in the field of distance education, affectivity and Digital Culture in teaching, such as Freire, Piaget, Wallon, Alves, Kensky, Fraga, among other experts and the current legislation linked to this discussion. This work found out that the role of the tutor in distance education in the context of Digital Culture is intrinsically related to pedagogical processes that aim at the humanistic ties with students, connecting feelings and virtual interaction simultaneously under different views to the teaching-learning process, triggering autonomy, desire, and motivation of the student's continuity. This study becomes a tool for information consultation for the construction of curriculum syllabuses that spark skills related to affectivity in higher distance education and that are in line with what the Base Nacional Comum CurricularBNCC (the Common Core National Curriculum) proposes for teacher training.

Keywords: Tutor. BNCC. Affection.

\section{RESUMEN}

El artículo tiene como objetivo presentar consideraciones relacionadas con el desempeño del tutor en Educación a Distancia - Educación a Distancia, en medio de las posibilidades presentadas en la enseñanza en el contexto de la Cultura Digital y las necesidades emergentes del uso de la afectividad en las relaciones personales y digitales para los estudiantes que caer en esta modalidad de enseñanza. El diseño de este trabajo se basa en la potencialización de la educación a distancia a través del trabajo afectivo del tutor que, a través de los atributos técnicos e inteligibles para los sensibles, puede contribuir a la permanencia del estudiante y, también, a la credibilidad y respeto de la sociedad con respecto a la enseñanza. EaD. Este estudio se basa en autores de renombre en el campo de la educación a distancia, la afectividad y la cultura digital en la educación, como Freire, Piaget, Wallon, Alves, Kensky, Fraga, entre otros académicos y la legislación actual vinculada a la discusión. El trabajo verificó que el desempeño del tutor en educación a distancia en el contexto de la cultura digital está intrínsecamente relacionado con procesos pedagógicos que apuntan al vínculo humanista con los estudiantes, conectando sentimientos e interacción virtual simultáneamente bajo diferentes perspectivas al proceso de enseñanza-aprendizaje, lo que desencadena la autonomía, deseo y motivación para la permanencia del alumno. Este estudio se convierte en un instrumento para consultar información para la construcción de menús curriculares que desencadenan habilidades relacionadas con la afectividad en la educación a distancia superior y están en línea con lo que propone la Base Curricular Común Nacional - BNCC para la capacitación de docentes.

Palabras clave: Tutor. BNCC. Afectividad.

\section{INTRODUÇÃO}

A modalidade de Educação a Distância (EaD) no Brasil vem expandindo-se historicamente e destaca-se na educação superior nas últimas décadas, principalmente na formação de professores e gestores através de programas e cursos ofertados pela Universidade Aberta do Brasil (UAB), que é responsável pela expansão e democratização do ensino público, em parceria com a União, entes federativos e municípios (BRASIL, 2006).

A EaD conecta variados perfis de agentes pedagógicos e dentre eles elencamos o tutor (presencial e a distância) como o principal representante institucional junto à mediação da aprendizagem, que exerce funções diversificadas e muitas delas de cunho 
pedagógico e em paralelo ao trabalho do professor, por isso neste estudo o denominamos de tutor pedagógico.

O tutor apresenta denominações e atribuições variadas perante a legislação, as quais discorrem este manuscrito, partindo do pressuposto da atuação pedagógica de tutoria para além dos requisitos formais da função, em vista de que o estudante contemporâneo tem características próprias frente ao processo social e cultural em que vive, fazendo uso dos mais variados meios e mídias móveis, característico do contexto de Cultura Digital. Frente ao exposto, o tutor pedagógico precisa manter vivo o diálogo e as estratégias de ensino no desejo de fazer persistir os estudantes no curso. Esse processo de acompanhamento atento acaba, por vezes, exigindo relações mais próximas junto ao estudante envolvendo, assim, a afetividade.

Este artigo aborda uma revisão conceitual e histórica sobre a EaD e o papel do tutor pedagógico no Brasil e tem por finalidade compreender os processos inerentes à atuação do tutor pedagógico, bem como as ações empregadas que podem potencializar não só o processo de ensino-aprendizagem dos estudantes, mas especialmente relações afetivas que dele emergem, especialmente no contexto de Cultura Digital.

Para discutir os temas propostos averiguamos estudos sobre afetividade com autores expressivos na área, tais como: Piaget (1993), Freire (1993) e Wallon (2015) e relacionamos suas abordagens de afetividade ao contexto atual na EaD, por meio de autores como Longhi (2011) e Fraga (2012) que abordam a comunicação e linguagem afetiva empregada nos processos de ensino, já que na EaD, temos que considerar as relações dos estudantes entre si, nos AVAs e com os tutores pedagógicos, pois este conjunto que vai motivar o estudante a permanecer no curso.

Compreender e desenvolver ações que envolvam afetividade na atuação do tutor pedagógico qualificam e dão ênfase para a EaD, perspectiva esta alinhada ao que abordam Rodrigues et al. (2015) em discussão acerca da potencialização da EAD, na qual consideram o afeto como um atributo essencial:

É instigante e desafiador considerar o fato de potencializar a EaD (Educação a Distância) apresentando as possibilidades que esta tem de produzir um tipo de conhecimento que pode se dar a partir de elementos técnicos e não menos potencializadores de afeto (RODRIGUES et al., 2015, p. 224).

As autoras Rodrigues et al. (2015) preveem que a EaD conquistará cada vez mais valor perante a sociedade por meio gradual e contínuo, gerando credibilidade e respeito, 
sendo o afeto um meio de garantir a permanência do aluno nos cursos em EaD, na qual o valor de quem ensina e aprende é permeado pela resposta a expectativa de acolhimento. Ressaltam ainda que o processo digital envolvido no aprender em EaD deve ocorrer em paralelo às questões humanas, de forma individualizada e de acordo com as necessidades de cada estudante.

O tutor pedagógico, portanto, tem entre suas funções, a de acompanhar atentamente o estudante da EaD, influenciando as relações e vínculos estabelecidos entre todos os estudantes em direção a sua persistência no curso. Nesse sentido caminha o objetivo deste trabalho, em oferecer visibilidade aos espaços construídos pelo trabalho do tutor pedagógico na $\mathrm{EaD}$, com intuito de colaborar na elaboração de práticas e programas que incluam a afetividade no trabalho do tutor pedagógico, ainda, potencializando e contribuindo com a literatura na área da EaD.

\section{Educação a distância- um pouco de sua história e funcionamento no Brasil}

Segundo alguns levantamentos históricos elencados por Alves (2007), a EaD existe desde o final do século XIX e passa ser assim denominada junto às políticas públicas a partir do art. 80 da LDB-Lei 9394 de dezembro de 1996, que regulamentou e deu reconhecimento a EaD em todos os níveis e modalidades de ensino (BRASIL, 1996). A Universidade Aberta do Brasil (UAB) hoje passa a ser uma importante propulsora de ações que, entre finalidades e objetivos sócio educacionais, que conectam a União e os entes federativos para ofertar programas em articulação com polos de apoio presencial nos municípios (BRASIL, 2006).

Segundo Alves (2007), a oferta de cursos profissionalizantes por correspondência já eram anunciados nos jornais do Rio de Janeiro cerca de seis anos antes da regulamentação formal no país. O autor evidencia também que esses anúncios estavam ligados a aulas direcionadas ao ensino de profissões, e ministradas por, em sua maioria, professoras particulares e não vinculadas a um estabelecimento formal de ensino, considerando que a instalação das Escolas Internacionais em 1904, como um marco de referência oficial que ofereciam cursos profissionalizantes por correspondência. Nos anos 1970, essa modalidade de educação encontrou-se estagnada no Brasil, apresentando decréscimo no cenário internacional (ALVES, 2009). 
Holmberg (1985), por exemplo, já na década de 80, determinou bases e fundamentos para a EaD, firmadas na comunicação e interação, determinando que a EaD ocorre em distintas formas de estudo, sob supervisão contínua, ou não, de tutores e professores, devendo possuir uma organização estrutural bem desenvolvida pedagogicamente. Em síntese, para o autor os processos de ensino-aprendizagem na EaD se apresentam de forma síncrona ou assíncrona e deve ser construído coletivamente e colaborativamente na busca do conhecimento. Mill (2018a) ressalta que a EaD é uma modalidade de ensino que pode ser planejada com outras modalidades, já que abrange todos os níveis e tem caráter próprio e diverso.

Desde o princípio de sua consolidação, a EaD enquanto modalidade de ensino almeja aos professores uma formação crítica e integral em espaços acessíveis e colaborativos em AVAS institucionais, com ênfase especialmente em " [...] um quadro de valores comuns, novos conhecimentos coletivamente construídos e práticas pedagógicas socializadas, refletidas e reelaboradas em conjunto" (ALMEIDA; PRADO, 2003, p. 75). Para Alves (2009), em mais de cem anos a EaD no país criou excelentes oportunidades educacionais, entre políticas e programas, que contribuíram para a democratização do ensino de qualidade, atendendo estudantes de regiões pouco favorecidas.

Segundo Boll et al. (2016) enquanto estudantes e professores estão separados “espacialmente e/ou temporalmente", o processo educador e de aprendizagem, institucionais ou não, se manifestam, complementando-se e estabelecendo-se como uma tecnologia didática. Em se tratando de licenciandos na EaD, o lugar do AVA e seus protagonistas, professores, tutores pedagógicos e estudantes, o que seria apoio, recurso ou ferramenta passa a ser a própria docência:

[...] Para os licenciandos na modalidade presencial a discussão e vivência de uma disciplina a distância é um incremento à ideia de que as tecnologias não são apoio, recurso ou ferramenta: são a própria docência. Portanto, neste lugar da EaD elas se constituem ética e esteticamente em processo de ensinos e aprendizagens (Boll et al. 2016,p. 2).

Apesar de a EaD apresentar, portanto, características próprias especialmente quando na formação de professores, ela também se destaca, como no art. $1^{\circ}$ do decreto n. 9057, de 25 de maio de 2017, enquanto mediação didático-pedagógica:

[...] Considera-se educação a distância a modalidade educacional na qual a mediação didático-pedagógica nos processos de ensino e aprendizagem ocorra com a utilização de meios e tecnologias de informação e comunicação, com pessoal qualificado, com políticas de acesso, com acompanhamento e avaliação 
compatíveis, entre outros, e desenvolva atividades educativas por estudantes e profissionais da educação que estejam em lugares e tempos diversos (BRASIL, 2017).

Nas últimas décadas, a EaD tem sido uma modalidade que apoia as políticas públicas para formação de professores, gestores e cidadãos em geral, sendo alternativa e complementar para a formação, com foco na democratização do ensino e no potencial pedagógico (MILL; MACIEL, 2013). Segundo Mill (2018a), a EaD se configura na relação com o ensino-aprendizagem como práticas logísticas e pedagógicas em contexto educacional digital. A criação da UAB surge no país e tem, entre os objetivos, o de garantir a oferta gratuita da EaD a nível superior. O Decreto $n^{\circ} 5.800 / 2006$, instaurou os objetivos principais, que estão dispostos no artigo Art. $1^{\circ}$ :

[...] Fica instituído o Sistema Universidade Aberta do Brasil - UAB, voltado para o desenvolvimento da modalidade de educação a distância, com a finalidade de expandir e interiorizar a oferta de cursos e programas de educação superior no País.

Parágrafo único. São objetivos do Sistema UAB:

I - oferecer, prioritariamente, cursos de licenciatura e de formação inicial e continuada de professores da educação básica;

II - oferecer cursos superiores para capacitação de dirigentes, gestores e trabalhadores em educação básica dos Estados, do Distrito Federal e dos Municípios;

III - oferecer cursos superiores nas diferentes áreas do conhecimento;

IV - ampliar o acesso à educação superior pública;

$V$ - reduzir as desigualdades de oferta de ensino superior entre as diferentes regiões do País;

distância; e

VI - estabelecer amplo sistema nacional de educação superior a VII - fomentar o desenvolvimento institucional para a modalidade de educação a distância, bem como pesquisa em metodologias inovadoras de ensino superior apoiadas em tecnologias de informação e comunicação (BRASIL, 2006).

O decreto evidencia, entre outros aspectos tão importantes como o objetivo de garantir a oferta gratuita da EaD a nível superior, a ampliação e democratização para a formação de professores entrecruzando com o uso das tecnologias e inovação nos processos de ensino-aprendizagem. Segundo Haddad (2006), a democratização da EaD proporciona o acesso dos jovens à educação superior pública, gratuita e de qualidade e vem a suprir a carência de professores na educação básica.

Enquanto democratização do acesso e permanência dos professores no ensino superior, a EaD tem sido uma principal aliada das políticas públicas em tempos de Universidade Aberta do Brasil contribuindo significativamente tal como nos diria Boll et al. (2016) para uma 'estética digital' que se fortalece principalmente quando o assunto é a 
formação de professores na modalidade da EaD. A EaD proporciona um ensino que utiliza-se de diferentes recursos tecnológicos, possibilitando a democratização do conhecimento e, especialmente, o acesso a ele em qualquer tempo e lugar através dos aplicativos e um celular móvel (UNESCO, 2014).

\section{O papel da tutoria na EAD no Brasil}

O termo tutoria na $\mathrm{EaD}$ vem sendo relacionado à atividade pedagógica de acompanhamento dos estudantes, apresentando concepções diversificadas e variadas, divergindo inclusive em suas funções e competências na literatura (MILL, 2018b).

Mill (2018b) enfatiza que, historicamente, no Brasil o tutor pedagógico vem recebendo alguns sinônimos, tais como: educador online, mentor, orientador virtual, monitor pedagógico, e-formador, formador virtual, entre outros. De acordo com Martins e Detoni (2013) o tutor aparece na medida em que na EaD se apresenta uma ruptura da relação física entre estudantes e professores presencialmente. Para os autores, portanto, o tutor é um mediador entre o professor, os conteúdos e os estudantes e sua função é necessária para verificação e acompanhamento da aprendizagem.

Nessa perspectiva Preti (2003) apresenta dois tipos de tutores, o tutor à distância, que faz a mediação do processo pedagógico com os estudantes pela própria instituição, o qual acontece através do AVA, sendo o responsável pela tutoria nas disciplinas, exercendo a função de mediador entre conteúdos e estudantes e o tutor presencial, que atende aos estudantes nos polos de apoio presenciais, este além de orientar os alunos em relação ao AVA, necessita estar presente em momentos presenciais, tais como avaliações, aulas, reuniões e outros, sendo mediador entre o curso (gestão do polo, secretarias acadêmicas, coordenação do curso, professores) e o estudante. Ao analisar a definição de ambos, verificamos que tanto o tutor à distância quanto o presencial desenvolvem atuação próxima e de cunho pedagógico com o estudante, sendo o segundo o mais próximo, por acompanhar o estudante em toda trajetória acadêmica.

A Resolução CD/FNDE No 26/2009 com redação atualizada pela Resolução Nº 8 CD/FNDE/MEC, de 30 de abril de 2010, define o tutor presencial como um profissional que atua no polo de apoio presencial, tendo sob sua responsabilidade uma turma de 25 a 50 estudantes do mesmo curso. O tutor presencial na EaD é definido como um agente que 
tem, em suas ações, a especial função de contribuir para o aprimoramento dessa modalidade, garantindo o acompanhamento full time de todo o processo educacional. Segundo o Sistema Nacional de Avaliação de Ensino Superior- SINAES (2017), Indicador 2.14:

[...] O corpo de tutores possui experiência em educação a distância que permite identificar as dificuldades dos discentes, expor o conteúdo em linguagem aderente às características da turma, apresentar exemplos contextualizados com os conteúdos dos componentes curriculares e elaborar atividades específicas, em colaboração com os docentes, para a promoção da aprendizagem de alunos com dificuldades, e adota práticas comprovadamente exitosas ou inovadoras no contexto da modalidade a distância. (SINAES, 2017, p.28).

De acordo com o indicador proposto pelo SINAES o tutor tem diversas atribuições na $\mathrm{EaD}$, dentre elas a responsabilidade de observar e intervir de forma cuidadosa às necessidades individuais dos estudantes. Corroborando com o exposto Costa (2013), refere-se à palavra tutor como: guia, protetor, diretor, fiscalizador, orientador, dentre outras funções, dependendo da perspectiva pedagógica adotada pelo modelo da EaD. Prado et al. (2012) complementa dizendo que o tutor tem papel fundamental na EaD, pois garante a inter-relação personalizada e contínua do estudante no sistema e, também, viabiliza a articulação necessária entre os elementos do processo e execução dos objetivos propostos.

As principais funções dos tutores, segundo Ruckstadter (2011), são: estimular e promover o contato entre estudantes, por meio de grupos de estudo, troca de e-mails, proporcionando a interação entre os envolvidos; ser o elo entre os conteúdos e os estudantes, motivando-os diante das dificuldades; ajudar na organização dos estudos; sugerir leituras complementares indicando sites, livros e periódicos, incentivando a pesquisa; estar apto a desenvolver processos avaliativos.

Diante da definição e funções de um tutor, pode-se afirmar que compete a ele orientar a aprendizagem dos acadêmicos. Para Argüis (2002), o tutor precisa possuir alguns requisitos, tais como: qualidades humanas, como empatia, sociabilidade, responsabilidade e capacidade de aceitação, qualidades científicas, como conhecimento da maneira de ser do estudante e dos elementos pedagógicos para identificar e ajudar o estudante e, além disso, qualidades técnicas, tais como saber trabalhar com eficácia e em equipe e participando de projetos. 
Para Costa (2013), o tutor precisa manter diálogo e relacionamento agradável com os estudantes, pois isso favorece a aprendizagem. O autor demonstra através de um exemplo empírico:

[...] O motivo de se destacar o diálogo entre os tutores decorre do fato de que nesse ambiente é possível extrapolar a mera indicação de uma leitura do livro texto, acrescentando informações complementares que enriquecem a abordagem dos conteúdos propostos na disciplina. Por tudo isso, conclui-se que está havendo uma mediação na comunicação professor-aluno em relação aos conteúdos trabalhados (COSTA, 2013, p. 114).

Em relação a linguagem empregada no diálogo, “[...] o tutor precisa ainda ser comunicativo, criativo e ter a escrita como uma prática, a fim de se fazer compreender com uma linguagem mais formal. O desafio do tutor é mediar o ensino de modo virtual" (RUCKSTADTER, 2011, p. 35). As atribuições elencadas formalmente ao tutor pedagógico são de importância visível ao funcionamento da EaD, já que possibilitam expressante responsabilidade e aproximação com os estudantes, quando acrescentadas de práticas afetivas de acordo com o contexto social e cultural de cada público, tornam-se potenciais para reconhecimento e crescimento positivo da EaD.

\section{Relação de afetividade entre tutor pedagógico e estudante}

Conforme elencado na seção anterior, existem dois tipos de tutores, definidos como tutor à distância e tutor presencial (PRETI, 2003), ao analisarmos a definição de ambos, verificamos que tanto o tutor à distância quanto o presencial desenvolvem atuação próxima e de cunho pedagógico com o estudante, em especial o segundo, por acompanhar o estudante em toda trajetória acadêmica, diante disto definimos o termo tutor pedagógico para este estudo, fazendo referência a ambos.

Ao abordar com ênfase a atuação pedagógica da tutoria vinculamos a compreensão da afetividade como responsável por apresentar subsídios importantes no desenvolvimento de estratégias que se empenham na qualificação do processo de ensino-aprendizagem. Nesse contexto, ressaltamos a teoria do desenvolvimento de Piaget (1993) na qual aspectos cognitivos e afetivos estão intimamente interligados para a construção do processo de aprendizagem. O autor corrobora em seus escritos com a importância da afetividade nas ações quando as discute relacionada a aprendizagem dos estudantes. Ele refere-se ao desenvolvimento afetivo: 
[...]a afetividade caberia então o papel de uma fonte de energia da qual dependeria o funcionamento da inteligência. Porém, não suas estruturas, da mesma forma que o funcionamento de um automóvel depende da gasolina, que aciona o motor, porém não modifica a estrutura da máquina (PIAGET, 1993, p. 188).

Neste sentido trazemos Freire (1996) para a discussão, por relacionar a afetividade ao processo educativo em várias de suas obras, pois infere que a prática educativa é estritamente humana, não sendo possível desvincular os sentimentos e as emoções do ato de aprender:

E o que dizer, mas sobretudo que esperar de mim, se, como professor, não me acho tomado por este outro saber, o de que preciso estar aberto ao gosto de querer bem, às vezes, à coragem de querer bem aos educandos e à própria prática educativa de que participo. Esta abertura ao querer bem não significa, na verdade, que, porque professor me obrigo a querer bem a todos os alunos de maneira igual. Significa, de fato, que a afetividade não me assusta, que não tenho medo de expressá-la. Significa esta abertura ao querer bem a maneira que tenho de autenticamente selar o meu compromisso com os educandos, numa prática específica do ser humano (FREIRE, 1996, p. 52).

Freire argumenta sobre a importância de explorar o sentimento do querer bem, apontando o estímulo da alegria frente aos desafios que envolvem o processo ensinoaprendizagem, argumentando que é falso considerar inconciliáveis a seriedade do professor e a alegria, já que sentimentos alegres e otimistas não são opositores da respeitabilidade e rigorosidade e sim aliados ao processo de ensino-aprendizagem.

Em síntese, Piaget aproximava inteligência e afetividade para além de uma visão dicotômica do aprender, propondo a necessária correspondência entre afetivo e cognitivo para os processos do aprender e da construção da aprendizagem e Paulo Freire colabora às discussões quando enfatizava em seus estudos a importância do diálogo e da prática afetiva nos processos de ensino.

Tanto Piaget quanto Freire se fortalecem na relação, na produção de sentidos para o aprender. Wallon é citado em vários estudos relacionados a EaD, Carvalho e Lima (2015) apoiados na concepção Walloniana para afetividade, sugerem que é importante a criação de laços na EaD, pois isso gera sensação de pertencimento aos estudantes, resultando em motivação no processo de ensino-aprendizagem. Para Wallon (2015), o ambiente é um requisito primordial ao aprendizado, seja ele presencial ou a distância, não sendo possível explicar a conduta de uma pessoa quando isola-se em relação ao ambiente no qual se desenvolve, logo, a afetividade é um requisito fundamental ao ato de apropriação do ambiente ao qual o estudante está inserido. Vasconcelos (2009) corrobora com as 
constatações Wallonianas e faz inferência da dimensão afetiva como atributo para modificação do currículo:

[...] um dos grandes desafios que encontramos hoje quando buscamos a transformação do currículo é a descrença do professor na viabilidade de mudança: por não vislumbrar possibilidade (dimensão cognitiva), acaba diminuindo o desejo de fazer, não se envolvendo no processo de mudança (dimensão afetiva). (VASCONCELLOS, 2009, p.65).

Ao analisarmos os autores clássicos da educação, percebemos que a preocupação em abordar afetividade no currículo faz parte da história da educação. Transpor para a EaD é um desafio aos profissionais que atuam nessa modalidade. Tijiboy et al.(2009) enfatizaram, por meio de um estudo de caso com estudantes de nível superior, que manifestações emocionais positivas, similares as que presenciamos em contextos educacionais presenciais, favorecem a realização de tarefas de cunho intelectual.

Segundo Tijiboy et al.(2009), no contexto da EaD, as interações no AVA exigem mais que habilidades técnicas por parte dos professores e tutores pedagógicos, mostrando-se eficazes ações que estabelecem o vínculo interpessoal, como disponibilidade interna, amor e afeto.

Nesta perspectiva elencamos Longhi (2011), que aborda o termo comunicação afetiva, como um "fenômeno afetivo" que é representado por meio de sons, escritas, gestos, comportamentos ou qualquer outra forma criativa. São os meios pelos quais os sentimentos se apresentam por meio da linguagem corporal e escrita, mas também por meio digital. É possível crer que dessa relação à linguagem afetiva produza sentidos no ambiente de aprendizagem digital, dos Ambientes Virtuais de Aprendizagem (AVA), conectando os estudantes presencialmente ou não e, até mesmo, instigando-os a maior participação.

Assim, a própria linguagem empregada nos processos de ensino-aprendizagem pode agir como motivação de cunho afetivo. Fraga (2012) específica à linguagem como parte do sensível. Segundo a autora:

A linguagem passa a ter caráter fundante dos sentidos comunicacionais, constituída no plano do sensível, da manifestação, enquanto criadora de efeitos ou crenças de realidades ou enquanto constituidora dos processos midiáticos de persuasão e interpretação subsumidos pelos primeiros (FRAGA, 2012, p. 124).

Segundo Rodrigues et al. (2015), cabe ao agente mediador, que na maioria das vezes é o tutor pedagógico, interpretar e contextualizar as colaborações que chegam ao ambiente virtual, motivando o estudante através do incentivo, sensibilizando inclusive os 
colegas e a turma, registrando o apoio aos seus processos de aprender, incluindo os problemas e as dificuldades enfrentadas como parte dele. Segundo Souza e Borges (2012):

[...] é preciso que o tutor compreenda e esteja atento aos aspectos humanos, tais como: perfis grupais, afetividade, estímulos para realização de atividades, e também aos aspectos técnicos, como conhecimento básico de informática e das ferramentas disponíveis, que significam apoio vital ao funcionamento da EaD. (SOUZA; BORGES, 2012, p.5).

Neste sentido abordagens afetivas e motivacionais no processo de informação e aprendizagem tendem a ser a principal meta educacional atual, já que fomentam a escolarização formal como capacidade autorregulada de aprendizagem e podem ser aliadas no processo de não evasão dos estudantes na EaD (BORUCHOVITCH, 2008). Tinto (2002) considera que aconselhamento e apoio são condições importantes de suporte à persistência de estudantes no ensino superior ao que cremos que, na EaD, esse fator na usabilidade dos espaços síncronos com chats e assíncronos como fóruns, por exemplo, passa a ser fundamental.

\section{Cultura digital- histórico e abordagem na BNCC, em consonância com a afetividade}

O termo Cibercultura é composto pelas palavras cibernética e cultura, conceituada como uma ciência relacionada as tecnologias, caracterizada pela comunicação mediada por computadores, que surge de posicionamentos contrários a discursos hegemônicos na década de 1960, voltados à razão, à ciência e à técnica, transformando-se em uma apropriação coletiva dos dispositivos. Assim, o surgimento do termo Cultura Digital não provém propriamente da informática, mas da microinformática na década de 1940, na qual o fato de que cada indivíduo pode ter em suas mãos um instrumento de produção de informação com o acesso à internet abriu a possibilidade de produção coletiva, colaborativa e distributiva da informação. O acesso à informação tornou-se universal e a disseminação de informação não necessitava mais de espaço geográfico, autorização ou recursos financeiros (LEMOS. Ronaldo, 2009).

Para compreender o termo Cultura Digital, Kenski (2018) define ambas as palavras que o compõem, onde cultura pode ser entendida como manifestação individual e/ou coletiva da produção humana em diferentes campos, espaços e tempo, em Kensky (2018, 
p. 139)“[...] cultura é uma soma de conhecimentos, valores e práticas vivenciadas por um grupo em determinado tempo, não necessariamente no mesmo espaço" e é neste quesito que se faz compreensivo o termo Cultura Digital. A palavra digital é conceituada como tecnologias que transmitem dados por sequência de números de 0 e 1, esses dados são convertidos em palavras, sons ou imagens por um sistema decodificador.

Assim ao unir os termos cultura e digital, define-se um momento particular da humanidade em que os meios digitais e de informação expandiram-se no século XX e na atualidade, relacionado a processos e procedimentos amplos em diversos setores da sociedade (KENSKI, 2018). A autora define Cultura Digital:

[...] Cultura Digital é um termo novo, atual, emergente e temporal. A expressão integra perspectivas diversas vinculadas às inovações e aos avanços nos conhecimentos, e à incorporação deles, proporcionados pelo uso das tecnologias digitais e as conexões em rede para a realização de novos tipos de interação, comunicação, compartilhamento e ação na sociedade (KENSKI, 2018, p. 139).

Kenski constatou que a expressão Cultura Digital é resultado dessa nova dinâmica ocasionada pela multiplicidade de produção de conhecimentos associado a diferentes tipos de compartilhamento. Dentro dessa perspectiva, Canevacci (2009) considera característica da Cultura Digital a relação estabelecida entre indivíduo e tecnologias, que favorece as potencialidades contemporâneas, o olhar para as informações introjetadas, compreendidas, associadas e modificadas. Essas modificações podem ser observadas na transformação da mídia que, há mais de duas décadas, trouxe muitas oportunidades de relações sociais, não possíveis até então. É como um trem que, ao chegar na cidade, modifica o contexto e modo de vida das pessoas. Para Lemos, André (2009) o início da era virtual trouxe novos acessos e formas de conexão, que reestruturaram a forma de fazer cultura, "[...] As mídias modificaram transversalmente todas as formas de relacionamento, impactando a cultura, a política, a ciência, o direito e a economia" (LEMOS, André, 2009, p.97).

$\mathrm{Na}$ educação formal as mudanças incorporadas pela Cultura Digital chegaram lentamente, enquanto, na educação informal há usuários de diferentes perfis e tipos sociais conectados, já que esta possui como características ser livre e aberta, na qual os sujeitos encontram-se interligados em redes e por conexões entre mentes (KERCKHOVE, 2009), este ato de libertação dos sujeitos da dependência do acesso à informação e ao 
conhecimento apenas por meios formais do ensino regular vem facilitando as práticas pedagógicas (KENSKI, 2018).

Segundo Silva (2010) o uso das tecnologias na educação auxilia no processo de ensino-aprendizagem, o qual perpassa pelo apoio às atividades, pela motivação dos estudantes e, gradualmente, dá lugar ao movimento de integração ao currículo da compilação de práticas sociais de estudantes e professores, típicos da Cultura Digital vivenciada no cotidiano. No contexto da EaD, para Ramos e Boll (2019), a Cultura Digital viabiliza um acesso rápido e diversificado por diferentes meios de informação possibilitando ao estudante receber e fornecer conhecimento por meio virtual e automatizado. As autoras ressaltam, também, que o sistema deve ter características que viabilizam a interação coletiva com significado aos estudantes. "A Cultura Digital dinamiza as relações comunicativas, estabelece novos processos sociais, amplifica as formas de acesso e disseminação da informação" (RAMOS; BOLL, 2019, p. 9).

Frente a essas diferentes e expressivas possibilidades observamos na Base Nacional Comum Curricular- BNCC (BRASIL, 2019b) a abordagem ao longo de toda sua redação a presença do termo Cultura Digital, aparecendo 37 vezes nas seções do documento, mostrando a importância de considerar o perfil digital do estudante atual nas instituições de ensino básico. O documento também define competências e habilidades que devem integrar os currículos escolares a partir do ano de 2020. Entre elas, vemos o socioemocional presente. Na BNCC, competência é um conceito definido como a mobilização de conhecimentos (conceitos e procedimentos), e habilidades (práticas, cognitivas e socioemocionais), atitudes e valores para resolver demandas complexas da vida cotidiana, do pleno exercício da cidadania e do mundo do trabalho.

A BNCC foi considerada dentro da temática deste estudo por ser o documento recente que norteia os currículos escolares do ensino fundamental e médio, considerando a Resolução Cne/Cp N², de 20 de Dezembro de 2019 que define as Diretrizes Curriculares Nacionais para a Formação Inicial de Professores para a Educação Básica e institui a Base Nacional Comum para a Formação Inicial de Professores da Educação Básica- BNCFormação (BRASIL, 2019a), a resolução define:

O $\S 8^{\circ}$ do art. 62 da LDB estabelece que os currículos dos cursos da formação de docentes terão por referência a Base Nacional Comum Curricular (BNCCEducação Básica);

A Lei ${ }^{\circ}$ 13.415, de 16 de fevereiro de 2017, em seu art. 11, estabelece o prazo de 2 (dois) anos, contados da data de homologação da BNCC-Educação Básica, para 
que seja implementada a referida adequação curricular da formação docente; (BRASIL, 2019a, p.1).

A resolução indica que os currículos dos cursos superiores de formação de professores serão reformulados até o ano de 2022, definindo que as aprendizagens serão garantidas aos estudantes do ensino básico através da formação dos professores, "art. 205 da Constituição Federal, reiterado pelo art. $2^{\circ}$ da LDB, requerem o estabelecimento das pertinentes competências profissionais dos professores" (BRASIL, 2019a, p.1).

Ainda é essencial ressaltar:

Art. $2^{\circ} \mathrm{A}$ formação docente pressupõe o desenvolvimento, pelo licenciando, das competências gerais previstas na BNCC-Educação Básica, bem como das aprendizagens essenciais a serem garantidas aos estudantes, quanto aos aspectos intelectual, físico, cultural, social e emocional de sua formação, tendo como perspectiva o desenvolvimento pleno das pessoas, visando à Educação Integral (BRASIL, 2019a, p.2).

O artigo 11 da resolução prevê a carga horária destinada aos estudos referentes a BNCC nos cursos de licenciaturas, lê-se "Grupo II: 1.600 (mil e seiscentas) horas, para a aprendizagem dos conteúdos específicos das áreas, componentes, unidades temáticas e objetos de conhecimento da BNCC, e para o domínio pedagógico desses conteúdos" (BRASIL, 2019a, p. 6).

Percebemos, dessa forma, que as competências e habilidades propostas para as escolas poderão resultar em mudanças curriculares na formação de professores em Ead, propondo que os licenciandos adquiram na prática para posterior utilização no trabalho dos professores. As Novas competências vêm evidenciando-se na Cultura Digital mediada, gerando possibilidades de acesso permanente e instantâneo dos dados, somando-se com as facilidades de interação e comunicação on-line, gerando o surgimento de comunidades e redes formadas por seres dispersos nas redes com o objetivo de aprendizagem em conjunto (KENSKI, 2018).

O documento da BNCC aborda a Cultura Digital como promotora de mudanças sociais significativas nas sociedades contemporâneas, apresentando o avanço e a multiplicação das tecnologias de informação e comunicação, fazendo referência ao crescente acesso a elas pela maior disponibilidade de computadores, telefones celulares, tablets e afins. Os estudantes estão inseridos dinamicamente nessa cultura, não somente no papel de consumidores, mas engajados como protagonistas da Cultura Digital, envolvendo-se diretamente em novas formas de interação multimidiática e multimodal e 
de atuação social em rede, que se realizam de modo cada vez mais ágil (BRASIL, 2019b). Cita ainda que:

[...] essa cultura também apresenta forte apelo emocional e induz ao imediatismo de respostas e à efemeridade das informações, privilegiando análises superficiais e o uso de imagens e formas de expressão mais sintéticas, diferentes dos modos de dizer e argumentar característicos da vida escolar (BRASIL, 2019b, p. 61).

A BNCC relaciona a habilidade emocional ao estudante oriundo do contexto da Cultura Digital, mostrando a necessidade emergente de relacionar o emocional e por consequência a afetividade nas relações virtuais de ensino. De acordo com Axt (2012), o grau elevado de "virtualização" nos ambientes tecnológicos e as emoções expressas dos sujeitos envolvidos, estão relacionados ao sensível e a sentimentalidade em vista de emoções positivas e emoções negativas dentro da interação e aprendizagem dos sujeitos no mundo do "virtual tecnológico".

Ao analisarmos os processos de ensino-aprendizagem na EaD voltados a afetividade com o estudante que vive em tempos de Cultura Digital, nos remetemos a Lyotard (1996), o autor aborda que antes de induzir a inteligência cognitiva, o estudante deve ser induzido a um sentimento ou sentimentalidade, que seria esta imediata e estaria relacionada à comunicação, que pode ser analisado sob o ponto de vista de uma recepção estética.

Saarni (1999) define a competência emocional como a demonstração da eficácia pessoal nos relacionamentos sociais oriundos da emoção, para a autora essa competência não pode ser separada do contexto cultural e está ligada a conceitos como compaixão, autocontrole, justiça e senso de reciprocidade. Segundo Vale (2009, p. 2) “[...] Quando a eficácia pessoal é aplicada aos relacionamentos sociais, a pessoa pode, ao mesmo tempo em que reage emocionalmente, aplicar os seus conhecimentos e a sua significação sobre as emoções". A partir destes conceitos situamos o estudante no contexto da Cultura Digital, o qual se encontra permeado de interações virtuais sintonizadas com suas emoções.

A nona competência da BNCC aborda a empatia e colaboração, descritas como: reconhecer e valorizar o outro, participar de grupos variados no âmbito social, ter empatia, saber se colocar no lugar do outro e compreender que as diferenças são 
importantes e contribuem para formação da nossa sociedade, e é essencial saber lidar com emoções vivenciadas nas relações sociais (GHIO et al., 2019).

A competência relacionada à empatia vem sendo discutida no âmbito da tutoria pedagógica na EaD, sendo evidenciada e reforçada para a construção das adaptações curriculares necessárias na formação de professores. Tenório et al. (2016) evidenciam em sua obra a influência da empatia na função exercida por tutores e, além disso, constataram a escassez de estudos sobre competências socioafetivas, que resulta na dificuldade de reconhecê-las dentro do contexto da EaD. Os autores destacam a categorização de competências socioafetivas do tutor pedagógico proposta por Aretio (2002) e discutida por Giannella et al. (2003), que seriam a capacidade de aceitação, cordialidade, honradez e empatia. Os autores esclarecem que:

A aceitação seria a habilidade do tutor de compreender a heterogeneidade de saberes dos alunos e de ajudá-los a se sentirem parte ativa do processo de ensino-aprendizagem. A cordialidade seria tratar os alunos com receptividade, sensibilidade, afeto e respeito, com intenção de estimular a autoconfiança. A honradez seria agir com ética, seriedade, responsabilidade, comprometimento e humildade, no intuito de criar uma relação tutor aluno baseada na confiança e honestidade. Por fim, a empatia seria a capacidade do tutor de identificar e entender as emoções e de transfigurar os papéis, buscando conhecer as necessidades individuais dos alunos (ARETIO, 2002; GIANNELLA et al., 2003 apud TENÓRIO et al. 2016. p. 2 ).

A relevância da abordagem da empatia como competência socioafetiva representa progresso no contexto da EaD, uma vez que aproxima e motiva o estudante nas interações virtuais de ensino, transpondo ao contexto de Cultura Digital. Freire já propunha, há mais de duas décadas, "a prática educativa é tudo isso: afetividade, alegria, capacidade científica, domínio técnico a serviço da mudança..." (FREIRE, 1996, p. 53) e as novas formulações curriculares ainda empenham-se para transpor isso a prática em todos os níveis de ensino e em especial a EaD por suas características diferenciadas.

\section{CONSIDERAÇÕES FINAIS}

Por meio deste artigo percebeu-se que a atuação do tutor pedagógico na EaD em tempos de Cultura Digital está intrinsecamente ligada a processos educacionais e pedagógicos que visam um vínculo afetivo com o estudante, conectando sentimentos e interação virtual simultaneamente. "[...] hoje a mobilidade oferecida pela Cultura Digital garante não só outras formas de sociabilidades na esfera da comunicação e da mídia, mas 
também outras formas de ensinar e aprender na esfera escolar" (BOLL et al., 2018, p.66). Quando o tutor pedagógico se aproxima do estudante, fazendo uso da afetividade e da inteligibilidade ao sensível para atrair e motivar no processo de ensino-aprendizagem que ocorre por meio do AVA e em momentos presenciais, abre-se um leque para a produção de sentidos e valorização da EaD.

A percepção da relevância sobre acessibilidade ao sensível sugere um melhor resultado nos processos de ensino, neste sentido corroboram com a ideia Rodrigues et al.(2015), ao afirmarem que a concepção do ensinar e aprender com base na afetividade é composta por uma 'relação de via dupla', na qual tutores pedagógicos e estudantes se relacionam sob o enfoque ético e a imagem torna-se de abertura à dialética que transpõe a EaD. A relação que se dá entre estudante e o uso das tecnologias favorecem as potencialidades atuais, transmitindo diferentes olhares para as informações absorvidas, compreendidas, compartilhadas e modificadas, as quais são características próprias da Cultura Digital. Fica evidente, no recente documento normativo da BNCC, a necessidade do uso de diversas competências no processo de ensino-aprendizagem no contexto da Cultura Digital.

As possibilidades de interação, de construção e de relacionamentos resultantes da Cultura Digital podem representar diferentes alternativas para o desenvolvimento afetivo e efetivo do estudante frente às dificuldades de sua trajetória educacional. Ao considerarmos a relevância sob o entendimento das emoções que podem ser desenvolvidas no estudante inserido na EaD estamos colaborando para a persistência dele no curso escolhido e além disso, compreendemos que o estudante atua como sujeito repleto de variáveis que vão além do desejo de estudar.

Neste sentido, a empatia é elencada por diversos autores como a principal habilidade no trabalho da tutoria pedagógica. Para Souza (2004,) uma tutoria torna-se 'sedutora' quando desenvolve uma relação atenta e respeitosa com os estudantes, proporcionando sintonia afetiva e capacidade de comunicação. A atenção e valoração do vínculo construído entre instituição de ensino superior e estudante, por intermédio da função exercida pelo tutor pedagógico, apresenta-se como possibilidade estratégica de melhoria do processo de permanência e persistência do estudante e, ainda, como meio de potencialização da EaD e seu reconhecimento pela sociedade. 
Este estudo de revisão torna-se um instrumento importante de consulta de informações e também de abertura de possibilidades para que instituições de nível superior considerem o que foi detectado, ao realizarem a construção de currículos e ementas para disciplinas de cursos na modalidade de EaD, principalmente no que diz respeito às adaptações que a Resolução Cne/Cp № 2, de 20 de dezembro de 2019 (BRASIL, 2019a) que prevê adequação dos currículos de licenciaturas e formação de professores em relação às competências e habilidades da BNCC para o ensino básico, através do desenvolvimento de competências socioemocionais e interação afetiva entre estudantes e tutores pedagógicos no meio digital, considerando o contexto de Cultura Digital em que o estudante contemporâneo está inserido.

\section{REFERÊNCIAS}

ALMEIDA, M. E. B.; PRADO, M. E. B. B. Criando situações de aprendizagem colaborativa. In: VALENTE, J. A.; ALMEIDA, M. E. B.; PRADO M. E. B. (Org). Internet e formação de educadores à distância. São Paulo: Avercamp, 2003.

ALVES, J. R. M. A história da educação a distância no Brasil. IPAE-Instituto de Pesquisas Avançadas em Educação, Ano 16, Revista n. 86, 2007. Disponível em: <http://www.ipae.com.br/pub/pt/cme/cme_82/index.htm>. Acesso em: 20 mar. 2020.

ALVES, J. R. M. A história da EaD no Brasil. In: LITTO, F. M.; FORMIGA, M. M. M. Educação a distância: o estado da arte. São Paulo: Pearson Education, 2009.

ARETIO, L. G. La educación a distancia: de la teoría a la práctica. Barcelona: Ariel, 2002.

ARGÜÍS, R. Tutoria: com a palavra o aluno. Porto Alegre: Artmed, 2002.

Associação Brasileira de Educação a Distância (Abed) (org). Censo Ead. Br: relatório analítico da aprendizagem a distância no Brasil. São Paulo: Pearson Education do Brasil, 2010.

Disponível

em:<http://www.abed.org.br/censoead/CensoEaDbro809_portugues.pdf> Acesso em: 20 mar. 2020.

AXT, M. Realidade virtual I: o que a percepção tem a ver com isso? In: FRAGA, Dinorá; AXT, Margarete. (Org.). Políticas do virtual: inscrições em linguagem, cognição e educação. São Leopoldo: Unisinos, 2012, p. 45-60.

BRASIL. Lei n. 9394, de 20 de dezembro de 1996. Lei de Diretrizes e Bases da Educação Nacional. Brasília: D.O.U., n.24. Disponível em:<http://www.planalto.gov.br/ccivil_03/Leis/L9394.htm> Acesso em 20 mar. 2020. 
BRASIL. MEC- Ministério da Educação. Decreto $\mathbf{n}^{\circ} \mathbf{5 . 8 0 0}$ de 8 de junho de 2006. Dispõe sobre o Sistema Universidade Aberta do Brasil - UAB. Brasília: Presidência da República, 2006. Disponível

em: <http://www.planalto.gov.br/ccivil_03/_Ato20042006/2006/Decreto/D5800.htm> Acesso em 20 mar. 2020.

BRASIL. MEC- Ministério da Educação. Decreto n. 9057, de 25 de maio de 2017. Regulamenta o art. 80 da lei n. 9394/1996 e revoga o decreto n. 5.622/2005 e o art. $1^{\circ}$ do decreto n. 6.303/2007. Disponível em:<http://www.planalto.gov.br/ccivil_03/_Ato20152018/2017/Decreto/D9057.htm> Acesso em 20 mar. 2020.

BRASIL. MEC- Ministério da Educação. Resolução FNDE/CD n 26, de 5 de junho de 2009. Estabelece orientações e diretrizes para o pagamento de bolsas de estudo e de pesquisa a participantes da preparação e execução dos cursos dos programas de formação superior, inicial e continuada no âmbito do Sistema UAB vinculados à CAPES. 2009. Disponível em: < http://www.fnde.gov.br/index.php/arqresolucoes2009/494.../download> Acesso em 27 out 2020.

BRASIL. MEC- Ministério da Educação. Resolução FNDE/CD n 8, de 30 de abril de 2010. Altera os incisos I a V do art. $9^{\circ}$, o $\S 1^{\circ}$ do art. 10 e o item 2.4 do Anexo I da Resolução CD/FNDE $n^{\circ} 26 / 2009$, que estabelece orientações e diretrizes para a concessão de bolsas de estudo e de pesquisa a participantes da preparação e execução dos cursos dos programas de formação superior, inicial e continuada no âmbito do Sistema Universidade Aberta do Brasil (UAB). 2010. Disponível em: <https://www.fnde.gov.br/fndelegis/action/UrlPublicasAction.php >. Acesso em: 20 jun. 2020.

BRASIL. MEC- Ministério da Educação, Conselho Nacional de Educação e Conselho pleno. Define as diretrizes curriculares nacionais para a formação inicial de professores para a educação básica e institui a Base Nacional Comum para a Formação inicial de professores da educação básica (BNCC-formação). Resolução cne/cp n 2, de 20 de dezembro de 2019, publicada no dou de 10/2/2020, seção 1, pp. 87 a 90, 2019a. Disponível em: <http://portal.mec.gov.br/docman/dezembro-2019-pdf/135951-rcpo02-19/file>. Acesso em: 20 mar.2020.

BRASIL. MEC- Ministério da Educação. Base Nacional Comum Curricular. Brasília: Ministério da Educação (MEC), 2019b. Disponível em: <http://basenacionalcomum.mec.gov.br/images/BNCC_EI_EF_110518_versaofinal_site.pdf $>$ Acesso em: 20 mar. 2020.

BOLL, C. I.; LOPES, R. C.; LUCHINI, N. A. Tecnologias móveis e educação a distância: mais do que criar aplicativos é preciso saber o que fazer com eles. : EnPED -Simpósio Internacional de Educação a Distância e Encontro de Pesquisadores em Educação a Distância, v. 1, set. 2016. p. 1-11. Disponível em: <http://sistemas3.sead.ufscar.br/ojs/index.php/2016/article/view/1742/739> Acesso em: 20 mar. 2020. 
BOLL, C. I.; CORBELLINI, S.; GALAFASSI, F. O Wikilivros e as mídias móveis: um exemplo de como as diretrizes curriculares nacionais para a educação básica podem ser reutilizadas, revisadas, remixadas e redistribuídas entre professores, gestores appers. In: Mariângela Bairros; Patrícia Marchand. (org.). Coordenador pedagógico: concepções e práticas. 1ed.Porto Alegre: Tomo Editorial, 2018, v. 1, p. 63-80.

BORUCHOVITCH, E. A motivação para aprender de estudantes em cursos de formação de professores. Educação, Porto Alegre, v. 31, n. 1, jan./abr. 2008. p. 30-38. Disponível em:<http://www.redalyc.org/html/848/84806405/> Acesso em 20 mar. 2020.

CANEVACCI, M. Comunicação Visual. São Paulo: Brasiliense, 2009.

CARVALHO, M. R.; LIMA, R. L. A Importância da afetividade na EaD: uma perspectiva de Wallon. Revista EDaPECl, São Cristóvão (SE), v. 15, n. 1. 2015. Disponível em: <https://seer.ufs.br/index.php/edapeci/article/view/3391/pdf>. Acesso em: 20 mar. 2020.

COSTA, M. L. F. Educação a distância no Brasil. Maringá: Eduem, 2013.

FRAGA, D. Seis propostas para a educação linguística na era da escrita com luz. In: FRAGA, Dinorá; AXT, Margarete. (Org.). Políticas do virtual: inscrições em linguagem, cognição e educação. São Leopoldo: Unisinos, 2012, p. 115-133.

FREIRE, P. Pedagogia da autonomia: saberes necessários à prática educativa. São Paulo: Paz e Terra, 1996.

GIANNELLA, T.R.; STRUCHINER, M.; RICCIARDI, R.M.V. Lições aprendidas em experiências de tutoria a distância: fatores potencializadores e limitantes. Tecnologia Educacional, vol. 31, n. 161/162, jan. 2003. Disponível em: <http://www.educacaopublica.rj.gov.br/biblioteca/educacao/0059.html> Acesso em: 20 mar. 2020.

GHIO,M; MÉLEGA, G. A; KORZENIESKI, V; SILVA,G; MASCARENHAS, R; SIQUEIRA.R.R.F; AGUIAR, R.M.A.M.M; CEZAR, H.V.A.S; QUEIROZ, K.S. Caderno pedagógico. Somos educação. n², 2019, $190 \mathrm{p}$.

HADDAD, F. Prefácio. In: Secretaria de Educação a Distância (Org.). Desafios da educação a distância na formação de professores. Brasília, DF: SEED, 2006. p.7- 9.

HOLMBERG,B. Educación a distancia: situación y perspectivas. Buenos Aires: Kapeluz, 1985 .

KENSKI, V. M. Cultura digital. in: MILL, D. (org). Dicionário crítico de educação e tecnologias e de educação a distância. Campinas, SP: Papirus, 2018, p. 139-144.

KERCKHOVE, D. Inteligencias en conexión: hacia una sociedad de la web. Barcelona: Gedisa, 2009. 
LEMOS, André. O que é a cultura digital, ou cibercultura? Cultura digital.br, Azougue editorial, 2009, p. 135-149. Disponível em: <http://culturadigital.br/files/2010/02/culturadigital-br-2.pdf> Acesso em: 20 mar. 2020

LEMOS, Ronaldo. Creative Commons In: SAVAZONI, R. COHN,S. Cultura digital.br, Azougue editorial, 2009, p. 97-103. Disponível em: <http://culturadigital.br/files/2010/02/cultura-digital-br-2.pdf> Acesso em: 20 mar. 2020.

LONGHI, M. T. Mapeamento de aspectos afetivos em um ambiente virtual de aprendizagem. Tese (Doutorado)- Universidade Federal do Rio Grande do Sul, Centro de Estudos Interdiciplinares em Novas Tecnologias na Educação, Programa de pós graduação em informática na educação. Porto Alegre, p. 273. 2011. Disponível em: <https://www.lume.ufrgs.br/bitstream/handle/10183/39578/000826422.pdf?sequence=1> Acesso em: 20 mar. 2020.

LYOTARD, J.F. Algo assim como: Comunicação... Sem comunicação. IN: PARENTE, A. (Org). Imagem máquina: a era das tecnologias do virtual. Rio de Janeiro: Ed. 34, 1996, p. 258-266.

MARTINS, J.; DETONI, D.J. Principais atribuições dos tutores na EaD. Anais XIII Coloquio de Gestión Universitaria en Américas, 2013, 11 p. Disponível em: <https://repositorio.ufsc.br/bitstream/handle/123456789/113255/2013032\%20\%20Principais\% 20atribui\%C3\%A7\%C3\%B5es\%20dos\%20tutores\%20Ead.pdf?sequence=1> Acesso em: 20 mar. 2020.

MILL, D. MACIEL, C. (org.) Educação a distância: elementos para pensar o ensinoaprendizagem contemporâneo. Cuiabá: EdUFMT, 2013.

MILL, D. Educação a distância. In: MILL, D. (org). Dicionário crítico de educação e tecnologias e de educação a distância. Campinas, SP: Papirus, 2018, p.198-203.

MILL, D. Tutoria na educação a distância. In: MILL, D. (org). Dicionário crítico de educação e tecnologias e de educação a distância. Campinas, SP: Papirus, 2018, p.656-659.

PIAGET, J. Gênese das estruturas lógicas elementares. Rio de Janeiro: Zahar, 1993.

PRADO, C.; CASTELI, C.P.M.; LOPES, T.O.; KOBAYASHI, R.M.; PERES, H. H. C.; LEITE, M.M.J. Espaço virtual de um grupo de pesquisa: o olhar dos tutores. Rev. esc. Enferm USP., São Paulo: USP, v. 46, n. 1, 2012, p. 246-251. Disponível em: <http://www.scielo.br/pdf/reeusp/v46n1/v46n1a33.pdf>. Acesso em: 20 mar. 2020.

PRETI, O. O estado da arte sobre tutoria: modelos e teorias em construção. Cuiabá/ Mt: Uab-ufmt, 2003. Disponível em: <https://setec.ufmt.br/uploads/files/pcientifica/tutoria_estado_arte.pdf> Acesso em 28 out. 2020. 
RAMOS, R. D.; BOLL, C. I. Educação em contexto de cultura digital: potências pedagógicas e possibilidades de visibilidade para o conhecimento científico escolar. \#Tear: Revista de Educação Ciência e Tecnologia, v.8, n.2, 2019, p. 1-12. Disponível em: <https://periodicos.ifrs.edu.br/index.php/tear/article/view/3570> Acesso em: 20 mar. 2020.

RODRIGUES, C.F.; ILHA, T. F.; FREITAS, A. S. Considerações sobre afeto e neurociência para ensinar e aprender na EAD, 2015, p. 223-234. In: SILUK, A.C.P., PAVÃO, S. M.O.Educação a distância: trajetórias de professores formadores para o atendimento educacional especializado, pE.com, RS, 2015, 415 p.

RUCKSTADTER, V. C. M. Tutoria e o processo de mediação em EaD. Maringá, 2011.

SAARNI, C. Competência emocional e autocontrole na infância. In: SALOVERY, P; SLUTER, J. D. A inteligência emocional da criança: aplicações na educação e no dia-a-dia. Rio de Janeiro: Editora Campus, 1999, p.54-84.

SILVA, M. G. M. De navegadores a autores: a construção do currículo no mundo digital. In: Anais do ENDIPE. Belo Horizonte. 2010.

SINAES- Sistema nacional de avaliação da educação superior: presencial e a distância. Inep/MEC - Instituto Nacional de Estudos e Pesquisas Educacionais Anísio Teixeira, Brasília, 2017. Disponível em: <http://download.inep.gov.br/educacao_superior/avaliacao_cursos_graduacao/instrumen tos/2017/curso_reconhecimento.pdf> Acesso em: 20 mar. 2020.

SOUZA, M. G. Arte da sedução pedagógica na tutoria em educação a distância. Anais de Congresso, 2010. Disponível em: <http://www.abed.org.br/congresso2004/por/pdf/001TC-A1.pdf> Acesso em: 20 mar. 2020.

SOUZA, E. R.; BORGES, F. V. A. Competências essenciais ao trabalho de tutoria: estudo bibliográfico. In: Simpósio Internacional De EaD. Encontro de pesquisadores em EaD, 2012, São Carlos. Anais...São Carlos, São Paulo, p. 1-8, 2012. Disponível em: <http://sistemas3.sead.ufscar.br/ojs/index.php/sied/article/view/178> Acesso em: 20 mar. 2020.

TIJIBOY, A.V., PEREIRA, E. A., \& WOICIECHOSKI,R.L. Interação com afeto: aprendizagem em ambientes virtuais de aprendizagem. Novas Tecnologias na Educação, Porto Alegre/RS, v. 7, n. 1, Jul. 2009. Disponível em: <https://seer.ufrgs.br/renote/article/view/13986/7878> Acesso em: 20 mar. 2020.

TINTO, V. Enhancing student persistence: connecting the dots. Wisconsin: The University of Wisconsin, 2002.

TENÓRIO, A.; COSTA, M. de F. A. C.; TENORIO, T. A influência da empatia como competência socioafetiva na atuação de tutores a distância. Revista Brasileira de Aprendizagem Aberta e a Distância da Associação Brasileira de Educação a Distância RBAAD da ABED, Rio de Janeiro, v. 15, n. 1, 2016, p.11-22. Disponível em: 
<http://seer.abed.net.br/index.php/RBAAD/article/view/270/204 >. Acesso em: 20 mar. 2020.

UNESCO. O futuro da aprendizagem móvel: implicações para planejadores e gestores de políticas. Brasília: UNESCO, 2014. Disponível em: <https://unesdoc.unesco.org/ark:/48223/pfo000228074> Acesso em: 20 mar. 2020.

VALE, V. Do tecer ao remendar: os fios da competência socio-emocional. Exedra, Coimbra, n. 2, 2009. p. 129-146. Disponível em: <https://webcache.googleusercontent.com/search?q=cache:067eFvdc80J:https://dialnet. unirioja.es/descarga/articulo/3398255.pdf $+\& c d=1 \& h l=p t-P T \& c t=c l n k \& g l=b r>$ Acesso em: 20 mar. 2020.

VASCONCELLOS, Celso dos S. Currículo: a atividade humana como princípio educativo. 2.ed. São Paulo: Libertad, 2009.

WALLON, H. Do ato ao pensamento. Petrópolis: Editora Vozes, 2015.

Recebido em: $28 / 06 / 2020$

Parecer em: 30/08/2020

Aprovado em: 20/11/2020 